ARCHIVO ESPAÑOL DE ARTE, LXXXII, 327

JULIO-SEPTIEMBRE 2009, pp. 273-284

ISSN: 0004-0428

\title{
LA RECEPCIÓN DE LA ESCULTURA ITALIANA EN LA POSGUERRA ESPAÑOLA: EUGENIO D’ORS Y CRISTINO MALLO
}

\author{
POR \\ Ana ARa FERnÁndeZ \\ Universidad de Zaragoza
}

En el presente artículo se analiza la recepción que tuvo la escultura italiana de artistas como Francesco Messina, Arturo Martini, Marino Marini o Giacomo Manzù, tanto en la crítica artística como en los propios escultores españoles. Sus obras, caracterizadas por la plasmación de figuras rotundas en situaciones cotidianas, fueron bien vistas a los ojos de críticos que, como el influyente Eugenio D’Ors, pretendían la recuperación de las raíces más clásicas del arte español al estilo del Novecentismo italiano. El escultor español Cristino Mallo fue uno de los artistas en los que el poso italianizante caló más hondo.

Palabras clave: Escultura; España; Italia; Años 40; Francesco Messina; Arturo Martini; Marino Marini; Giacomo Manzù; Cristino Mallo; Eugenio D’Ors.

This article examines the impact of Italian sculpture by artists such as Francesco Messina, Arturo Martini, Marino Marini or Giacomo Manzù on both art criticism and sculptors in Spain. Their works, characterized by the capture of expressive figures in ordinary situations, were well-received by critics like the influential Eugenio D'Ors, who aspired to recuperate the classical roots of Spanish art in the style of the Italian Novecento art movement. This Italian influence made an extraordinarily deep impression on the Spanish sculptor Cristino Mallo.

Key words: Sculpture; Spain; Italy; 1940's; Francesco Messina; Arturo Martini; Marino Marini; Giacomo Manzù; Cristino Mallo; Eugenio D’Ors.

\section{¡Italia vuelve!}

“Italia vuelve" proclamaba Eugenio D’Ors en La Gaceta Literaria en mayo de 19301'; título éste demasiado triunfalista para el mensaje que pretendía transmitir: la decadencia, que según su

${ }^{1}$ D’Ors, E., "Italia vuelve", en La Gaceta Literaria, n. ${ }^{\circ}$ 81, 1-V-1930, p. 8. 
opinión, había sufrido el arte italiano durante todo el siglo XIX y primeras décadas del XX, señalando a Giovanni Segantini y a Medardo Rosso como los únicos artistas italianos que merecían ser destacados de esa aparente mediocridad. El Novecento italiano fue, sin embargo, el escenario donde salieron a la luz tres pintores por los que D’Ors siempre manifestó sus intereses artísticos: Carlo Carrá, Giorgio De Chirico y Mario Tozzi.

No pretendo en este artículo analizar ese período histórico ${ }^{2}$, sino avanzar hasta la década de la inmediata posguerra española para ahondar, en primer lugar, en los intereses de D'Ors para que el arte español realizado en aquellos años siguiera una orientación "clásico-mediterránea al estilo del novecentismo italiano", , deseo compartido junto a un buen grupo de intelectuales falangistas como Pedro Laín y Rafael Sánchez Mazas en un intento de crear un estilo nacional unitario frente al arte académico que triunfaba en las Exposiciones Nacionales de Bellas Artes.

Posteriormente centraré la atención en los artistas españoles, y muy especialmente en la figura del escultor Cristino Mallo, quienes bebieron y se dejaron influir por la estética de algunos artistas italianos en consonancia con el "ritorno all'ordine" que lideró el periodo artístico de entreguerras.

Las vivencias, en España e Italia, de un sistema dictatorial estrecharon inevitablemente los lazos entre ambos países y así, como recuerda Calvo Serraller, si durante la Guerra Civil española Italia tomó partido por Franco y en la Exposición Mundial de 1937 de París la España republicana mostraba el Guernica de Picasso, el pabellón del Vaticano ofreció a los franquistas un espacio para su autopresentación ${ }^{4}$. Al año siguiente, Mussolini invitó a la España franquista a la XXI edición de la Bienal de Venecia siendo el mismo Eugenio D'Ors el comisario del pabellón español y el encargado de seleccionar a los artistas que debían representar a nuestro país.

Son numerosas las referencias escritas por D'Ors que fueron publicadas, por lo general, en el periódico del régimen Arriba, en las que alababa el arte italiano en un intento de aleccionar y de guiar a los artistas españoles en el "richiamo all'ordine" que años antes habían defendido el grupo italiano "Valori plastici" retomando los principios del arte clásico y del Renacimiento.

D’Ors no fue el único crítico español que valoró en su justa medida las obras de los artistas italianos; posteriormente, y con suficiente perspectiva histórica, fue José María Moreno Galván quien llegó a afirmar que "ese mediterraneísmo solar, clasicista e imperial, propuesto como regeneración de la vanguardia, ilustra el porqué del interés por el arte italiano durante estos años de la postguerra", para concluir afirmando que "el clasicismo novecentista italiano venció a la Escuela de París"6.

Recientemente ha sido Guillermo Solana el encargado de retomar de forma general este tema advirtiendo que la atención prestada a la Escuela de París a la hora de estudiar la pintura española de la posguerra ha hecho olvidar la influencia recibida por parte del arte italiano contemporáneo ${ }^{7}$.

\footnotetext{
${ }^{2}$ Para el estudio del intercambio artístico entre Italia y España entre 1910 y 1939, véase: VV.AA., Cultura italiana e spagnola a confronto: anni 1918-1939, Tübingen, Stauffenburg, 1992.

${ }^{3}$ Calvo Serraller, F., ¿Aislamiento internacional o vacío social? Reflexiones sobre el arte español de la década de los cuarenta a través de las exposiciones", en cat. exp. Arte para después de una guerra, Madrid, 1993, p. 72.

${ }^{4}$ Calvo Serraller, V., España, medio siglo de arte de vanguardia, 1939-1985, Fundación Santillana, Madrid, 1985 , p. 116.

5 Moreno Galván, J. M., La última vanguardia, Magius, Madrid, 1969, p. 73.

${ }^{6}$ Moreno Galván, J. M., Op. cit., p. 74.

7 Solana, G., "Un cierto aire italiano. Resonancias del exterior en los años cuarenta", en cat. exp. Tránsitos. Artistas españoles antes y después de la Guerra Civil, Madrid, 1999, p. 137.
} 


\section{La escultura española de posguerra: unas breves pinceladas}

Son numerosos los estudios publicados sobre la vida artística española en los años sucesivos al final de la Guerra $\mathrm{Civil}^{8}$. En líneas generales, todos ellos coinciden en considerarla una época pobre en la realización de obras de arte dignas de ser remarcadas, a excepción de las creadas por los artistas exiliados fuera del país.

En este contexto histórico-artístico, el panorama de la escultura era si cabe más desolador. El elevado coste de los materiales y la inexistencia de un mercado artístico que valorara este tipo de obras, hizo mermar su producción considerablemente. Los encargos de imágenes religiosas que sustituyeran a aquellas que habían sido destruidas durante la contienda, fueron la principal fuente de trabajo de los escultores que permanecieron en España durante estos años.

Así, mientras los escultores estuvieron caracterizados, a lo largo de estos años, por "una absoluta incapacidad teórica para definir nuevos códigos conceptuales y lingüísticos para una escultura que se sabía había de ser forzosamente realista, católica, conmemorativa, legendaria, heroica y española"9 según Gabriel Ureña, para José Marín-Medina la escultura "era arrastrada hacia el ramplón formalismo y hacia los viejos cánones del barroquismo de la imaginería policromada y del aséptico neoclasicismo"10.

Como excepción señalamos la obra de dos artistas catalanes, Enric Casanovas y Josep Clará, cuyos desnudos femeninos, concebidos como símbolos de eternidad, lideraron la línea tradicional que triunfó en la época de posguerra. Su estilo se enmarcaba dentro del término "Noucentismo" tan defendido por D'Ors y cuya pretensión era la recuperación de las raíces más clásicas del arte catalán.

El crítico Juan Cortés destacaba de Clará "su perpetua adhesión a unos ideales de limpieza, orden y mesura" 11 con motivo de la sala dedicada por completo a su obra en la III Bienal Hispano-Americana de Arte (1955). La rotundidad de los desnudos femeninos de la obra de Aristide Maillol fue su referente plástico más inmediato; el escultor francés influyó decisivamente, como veremos posteriormente, en las obras de juventud de los escultores del "Novecento" italiano.

En líneas generales podemos afirmar que, en lo que a escultura se refiere, la actividad expositiva de los años cuarenta quedó reducida a las innumerables obras de escasa calidad que cada año se daban cita en las Exposiciones Nacionales de Bellas Artes. Moisés de Huerta, José Capuz, Juan Adsuara o Enrique Pérez Comendador, profesores todos ellos en la Escuela Superior de Bellas artes de San Fernando, fueron sólo algunos de los escultores de obras de corte academicista que triunfaban durante esta época.

\footnotetext{
8 Para el estudio de este periódico artístico, conviene consultar: AgUilera Cerni, V., Panorama del nuevo arte español, Ediciones Guadarrama, Madrid, 1966; AgUILERA CERni, V., Iniciación al arte español de la postguerra, Península, Valencia, 1970; Bonet Correa, A. (coord.), "Arte del franquismo", Cuadernos de Arte Cátedra, n. ${ }^{\circ}$ 13, Madrid, 1981; Calvo Serraller, F., Del futuro al pasado. Vanguardia y tradición en el arte español contemporáneo, Alianza Forma, Madrid, 1988; CABrera GarCíA, M. ${ }^{a}$ I., Tradición y vanguardia en el pensamiento artístico español (1939-1959), Universidad de Granada, Granada, 1998; Cirici Pellicer, A., La estética del franquismo, Gustavo Gili, Barcelona, 1977; Llorente HernáNDEZ, A., Arte e ideología en la España de la postguerra (1939-1951), Universidad Complutense de Madrid, Madrid, 1992; UreñA, G., Las vanguardias artísticas en la postguerra española: 1940-1959, Istmo, Madrid, 1982.

9 Ureña Portero, G., "La escultura franquista: espejo de poder", en Bonet Correa, A. (coord.), "Arte del franquismo", Cuadernos de Arte Cátedra, n. ${ }^{\circ}$ 13, Madrid, 1981, p. 79.

10 Marín-Medina, J., La escultura española contemporánea (1800-1978). Historia y evolución crítica, Edarcón, Madrid, 1978, p. 191.

${ }^{11}$ Cortés, J., "La escultura en la III Bienal”, en Goya, n. ${ }^{\circ}$ 8, septiembre-octubre 1955, p. 79.
} 
Al margen de estos certámenes oficiales se sitúa la obra de Ángel Ferrant, figura clave de la inmediata posguerra, cuyas esculturas contribuyeron a la recuperación del ambiente vanguardista que emergió en los años treinta.

\section{¿Y la escultura italiana? Martini, Messina, Marini y Manzù}

Si éste era el ambiente que se vivía en España, para comprender el desarrollo que experimentó esta práctica artística en Italia, y teniendo en cuenta sus diferentes condicionantes históricos, debemos remontarnos al periodo de entreguerras.

Tras la muerte de Medardo Rosso en 1928, Italia perdía a una de sus figuras claves para la renovación del arte escultórico. Según Umberto Boccioni, y así lo escribía en su Manifesto tecnico della scultura futurista (1912), Rosso fue el único "gran escultor moderno que intentó abrir la escultura a un campo más amplio, de dotar a la obra de la influencia de un ambiente y de las relaciones atmosféricas que lo unen al sujeto"12.

En el desarrollo de la década de 1930, la necesidad de dotar al arte italiano de una huella clásica, como se había pretendido hasta ese momento, se sustituyó por una voluntad que podríamos considerar "romántica" al surgir una noción de arte ligada a la "percezione quotidiana" de la realidad individual de cada artista, como tan acertadamente ha señalado Paolo Fossati ${ }^{13}$; una tendencia que alcanzó su máxima expresión en la década siguiente de la mano de artistas como Arturo Martini, Francesco Messina, Marino Marini y Giacomo Manzù. Fue en este momento cuando la escultura italiana retomó la vía figurativa como un vocabulario apto en la transmisión de mensajes artísticos propios de la modernidad.

De todos ellos fue quizá Manzù el que mayor fama alcanzó en vida al recibir el respaldo y apoyo de dos de los críticos italianos más influyentes del momento: Giulio Carlo Argan y Cesare Brandi; este último lo consideró con motivo de una exposición antológica en Florencia, "el escultor vivo más grande", siendo -según sus palabras- "el único escultor moderno que se conecta a la luz de Donatello"14 (fig. 1).

El éxito de estos artistas italianos residió en haber sabido encontrar un lenguaje que, permaneciendo unido a la figura humana, fuera al mismo tiempo moderno y libre de los condicionamientos académicos. Sin embargo, los resultados obtenidos no fueron homogéneos; así mientras Francesco Messina pretendía la recuperación de la más pura tradición italiana, por temática y estilo, Arturo Martini, Marino Marini y Giacomo Manzù apostaron por soluciones más novedosas basadas en las composiciones y las calidades de los materiales empleados.

Todos los escultores citados, a excepción de Martini, nacieron a comienzos del siglo XX lo que supuso que el estallido de la Segunda Guerra Mundial interrumpiera en un momento clave en la definición de su lenguaje artístico. Si la repercusión estilística en sus obras no fue ni mucho menos homogénea, todos ellos coincidieron en considerar los años de guerra y los inmediatamente posteriores, antes de la apertura internacional, como una época difícil.

\footnotetext{
12 "Grande scultore moderno che abbia tentado di aprire alla scultura un campo più vasto, di rendere con la plastica le influenze d'un ambiente e i legami atmosferici che lo avvincono al soggeto", en Boccioni, U., Manifesto tecnico della scultura futurista, Milán, 1912.

${ }^{13}$ Fossati, P., Materiali: arte italiana 1920-1940 nelle collezioni della Galleria Civica d'Arte Moderna di Torino, Musei Civici Torini, Turín, 1981, p. 171.

14 "Il piu grande scultore italiano vivente", "il solo scultore moderno che si ricollega alla luce di Donatello", en Brandi, C., "Manzù a Firenze", cat. exp. Giacomo Manzù, Florencia, 1986.
} 


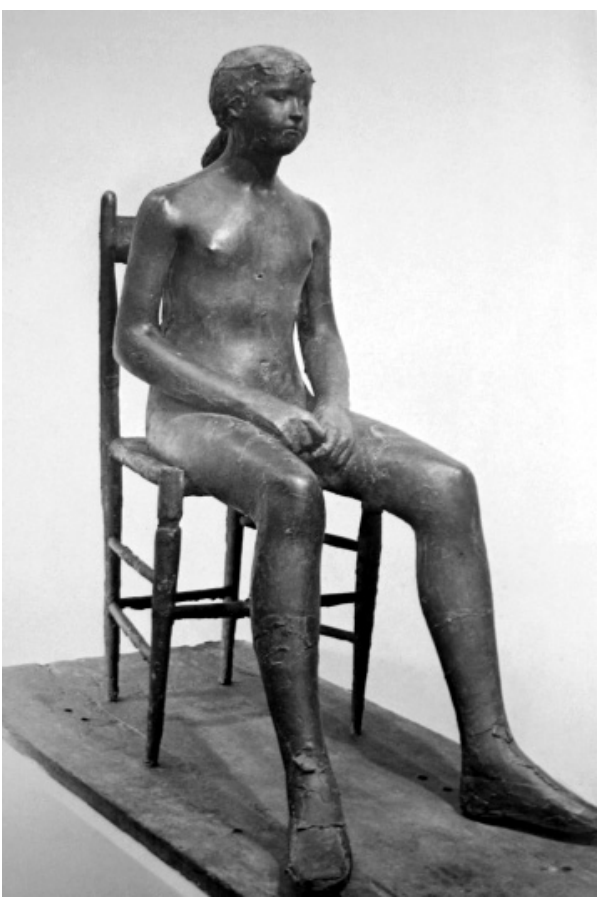

Fig. 1. Giacomo Manzù, Bambina sulla sedia (1949).

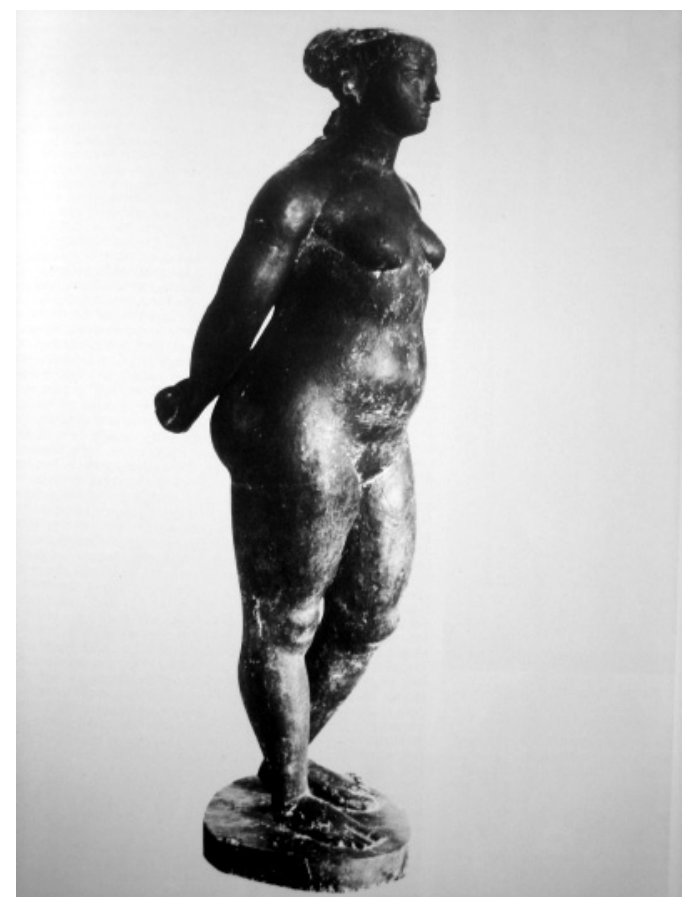

Fig. 2. Marino Marini, Pomona (1940).

Así, Arturo Martini publicó recién finalizada la guerra su famoso manifiesto La scultura lingua morta $^{15}$, en el que se interrogaba sobre la funcionalidad y significado de la escultura afirmando que "La escultura es lo que es: lengua muerta que no es común, ni podrá ser nunca palabra espontánea entre los hombres"16; mientras que Francesco Messina recordaba en sus memorias los "años penosos y de profunda desorientación que siguieron inmediatamente a la guerra. Especialmente los inviernos, con las garras todavía ensangrentadas"17.

Estos artistas no sólo sufrieron daños morales, la violencia de la guerra alcanzó a sus propias obras; así durante el bombardeo sobre Milán de 1941, Marino Marini veía cómo su estudio se destruía con todas las esculturas que en él albergaba (fig. 2).

Los éxitos internacionales de estos artistas no se hicieron esperar. Finalizada la guerra se multiplicaron las exposiciones, tanto individuales como colectivas. Sus esculturas amables y fácilmente comprensibles, cautivaron a un amplio público aterrorizado por las escenas de violencia vistas durante la contienda. Así, en 1960 se inauguraba una exposición colectiva en el Museo Rodin de París bajo el título Sculpture italienne contemporaine. D'Arturo Martini à nos jours, en la que estuvieron representados todos y cada uno de los escultores italianos citados.

\footnotetext{
15 Martini, A., La scultura lingua morta, Tipografia Emiliana, Venecia, 1945.

16 "La scultura resta quello che è: lingua morta che non ha volgare, né potrà mai essere parola spontanea fra gli uomini”, en PontigGiA, E., La scultura lingua morta e altri scritti, Abscondita, Milán, 2001, p. 48.

17 "Anni penosi e di grave disorientamento quelli che seguirono inmediatamente la guerra. Specialmente gli inverni, con gli artigli ancora insanguinati”, en Messina, F., Poveri giorni, Rusconi, Milán, 1974, p. 164.
} 


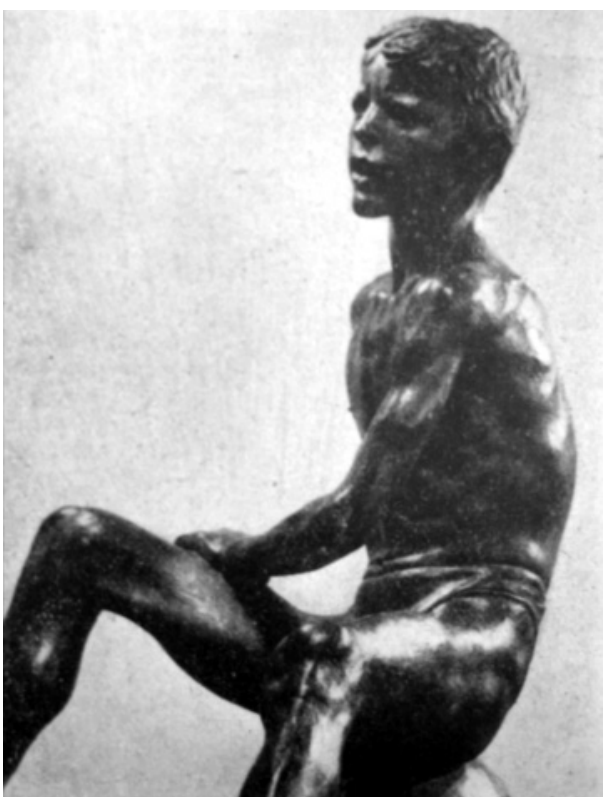

Fig. 3. Francesco Messina, Bambino al mare (1934).

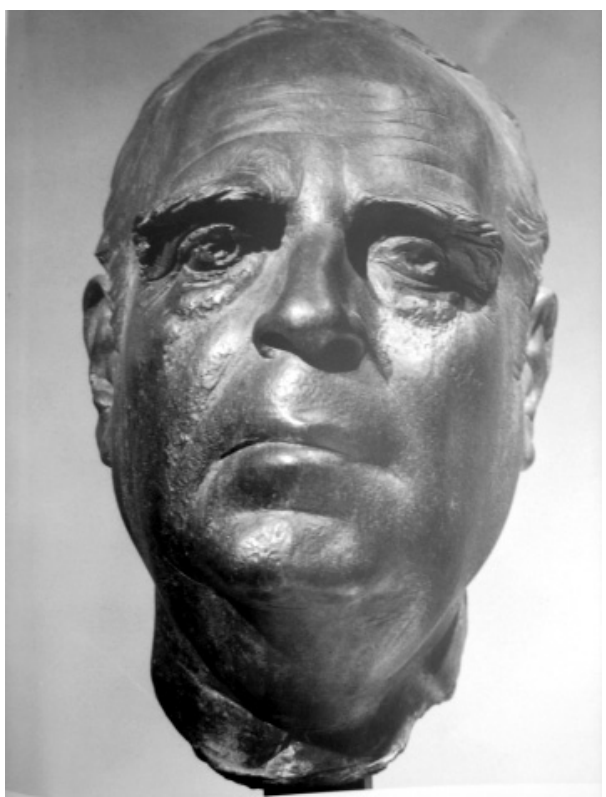

Fig. 4. Francesco Messina, retrato de Eugenio D’Ors (1949).

\section{Dos exposiciones de arte italiano en Madrid}

Con el título de Exposición de arte italiano contemporáneo fue celebrado en mayo de 1948 en el Museo Nacional de Arte Moderno de Madrid una muestra dedicada a la obra de veintiocho artistas italianos ${ }^{18}$. La Galleria del Cavallino de Venecia fue la encargada de su organización y Marino Bonini el autor del prólogo del catálogo.

Francesco Messina, Giacomo Manzù y el recién fallecido Arturo Martini, fueron los escultores allí representados. El primero de ellos expuso Niño en el mar (1934) (fig. 3), escultura con la que realizaba una interpretación del Hermes de Herculano, obra conservada en el Museo Arqueológico Nacional de Nápoles, y que ejemplificaba a la perfección la atemporalidad y belleza eterna con la que pretendía dotar a todas sus figuras en esta época, retornando a un naturalismo de impronta clásica.

Manzù estuvo presente con un ejemplar de su serie iniciada hacia 1938 de los Cardenales, sobre la que Eugenio D’Ors comentó en esta ocasión que era “el envío de más chiste de la exposición"19, mientras que de Marino Marini se eligió un Pequeño desnudo.

Una pieza llevada a cabo en 1935, paralelamente a la producción de escultura pública que por esos años realiza, fue la que representó a Arturo Martini con el título del Juicio de Salomón y que se enmarcaba dentro de una serie de piezas de pequeño formato.

\footnotetext{
${ }^{18}$ Sobre esta y otras exposiciones llevadas a cabo en España en este periodo, véase: ARA FERNÁNDEZ, A., "Una experiencia inédita en España: las exposiciones de escultura al aire libre”, Espacio, Tiempo y Forma, serie VII, vol. 17, 2004, pp. 239-262.

19 D’Ors, E., “Novísimo Glosario: los versátiles y los obstinados”, Arriba, 28-V-1948.
} 
Desde el Museo Nacional de Arte Moderno de Madrid, se entendió que la llegada de obras extranjeras era una buena ocasión para la ampliación de sus fondos, de ahí que fueran adquiridas algunas de ellas ${ }^{20}$.

Siete años después, tuvo lugar en la capital española otra exposición dedicada de forma monográfica al arte italiano. El fallecimiento de Eugenio D’Ors en septiembre de 1954 privó a los lectores de sus comentarios artísticos.

Entre mayo y junio de 1955 se celebró la Exposición de Arte Italiano Contemporáneo en el Palacio del Retiro de Madrid, bajo el patrocinio de la Dirección General de Bellas Artes y el Instituto de Cultura Hispánica. Esta muestra, junto con la organizada meses antes en el Palacio de la Virreina de Barcelona sobre pintura italiana contemporánea, fueron presentadas como los prolegómenos a la III Bienal Hispano-Americana de Arte que en otoño de ese mismo año iba a celebrarse en la ciudad condal.

En esta ocasión se amplió el número de expositores a diecisiete, alcanzándose un total de treinta obras. Entre ellas destacaban por su modernidad las piezas de los escultores Umberto Boccioni, Lucio Fontana y Mirko Basaldella, junto a las obras menos arriesgadas de Giacomo Manzù, Marino Marini, Francesco Messina y Emilio Greco.

\section{Recepción crítica del puño y letra de Eugenio D’Ors}

La celebración de dos muestras monográficas dedicadas al arte italiano contemporáneo no fue mera casualidad. Como señalábamos al comienzo de este artículo, en el transcurso de los años cuarenta, en el intento de crear un estilo español propio, se tomó como modelo la vuelta al orden y a la tradición que había sido promovido por el arte italiano de entreguerras y defendido por Mussolini. Esta tendencia establecía una gran conexión con el "Noucentisme" catalán y los principios promulgados por D'Ors a comienzos del siglo XX con los que se pretendía retomar las raíces mediterráneas de Cataluña.

La Academia Breve de Crítica de Arte creada por D’Ors supuso, durante la posguerra española -según palabras de Miguel Cabañas-, "una tentativa moderada de enlazar, sin olvido de la tradición renovadora autóctona, con el arte moderno en leve visión cosmopolita"21. No es por lo tanto extraño que D’Ors hiciera pública su satisfacción en 1948 por la celebración de una exposición de arte italiano al estar en la línea de las actividades promovidas por la Academia:

"Nada más acorde con la línea de servicio de la Academia Breve de Crítica de Arte que el haber traído a Madrid una exposición de artistas italianos de nuestros días"22.

En este mismo año, una obra del escultor Arturo Martini estuvo presente en la IV muestra antológica de la Academia Breve de Crítica del Arte. Sobre esta escultura comentaba D’Ors en esta ocasión: "no digo ya que sea una de las once mejores obras de arte expuestas en Madrid durante el año, sino, tal vez, la de perduración más segura. Demos gracias de su cesión al comendador Carlo Cardazzo, organizador de la Exposición italiana, ahora aquí abierta y que tan preciosa colaboración trae a los designios de la Academia Breve"23.

\footnotetext{
20 Tengo constancia de la compra de Bambina sulla sedia de Giacomo Manzù, Susanna de Arturo Martini y Bambino al mare de Francesco Messina (de este último se compra un Busto de niño en bronce que no consta en el catálogo de ninguna de las muestras comentadas).

${ }^{21}$ Cabañas Bravo, M., Política artística del franquismo. El hito de la Bienal Hispanoamericana de Arte, CSIC, Madrid, 1996, p. 62.

${ }^{22}$ D’Ors, E., "Novísimo Glosario: Arte italiano contemporáneo", Arriba, 25-V-1948.

23 D’Ors, E., Catálogo IV Exposición Antológica de la Academia Breve de Crítica del Arte, Madrid, 1948, s/p.
} 
En el campo que nos ocupa, la escultura, la combinación que los artistas italianos realizaban entre tradición y modernidad, correspondía exactamente a lo que desde este organismo se promovía. D'Ors llegó a calificar estas esculturas italianas como el clasicismo más puro que hubiera podido conocer el mundo contemporáneo analizando con acierto el estilo de cada uno de sus protagonistas desde las páginas del periódico Arriba:

"Ejemplar renacimiento, en conjunto, de la pintura italiana en el siglo XX. El de la escultura más. El arcaísmo en que a veces se dirían estilizadas estas grandes creaciones, no es una cosa postiza, como lo fue en Bourdelle. Con tanta y tan caliente intensidad de vida como en Maillol se puede encontrar a Martini quien muestra en sus obras el dominio de una acendrada vocación de belleza.

Si Martini evoca al Miguel Ángel de los Esclavos o del Entierro de Cristo, Francesco Messina no desmerece del Donatello del Or San Michel. Ni desde la derecha ni desde la izquierda hay posibilidad de objetar nada contra tamaña perfección.

Lo que Benlliure, mejor orientado y con mejor gusto hubiera podido ser lo que pudo constituir el ideal de un Pablo Gargallo con más sabiduría y menos travesura, se juntan en el arte equilibradísimo de Francesco Messina. Calidad triunfante la suya, no lo ha sido con peor fortuna la de Marino Marini. Los encargos -los oficiales y los intencionados inclusive- han tomado con él, igual camino que las dificultades y recogidas admiraciones"24.

A esta clara admiración por el arte italiano se sumaba la amistad que D’Ors mantenía con uno de los escultores italianos más importantes del momento, Francesco Messina, quien propuso al crítico español durante uno de sus múltiples viajes a Italia como el autor del prefacio de uno de sus catálogos ${ }^{25}$ que fue editado posteriormente ${ }^{26}$.

Durante este viaje, el escultor realizó un retrato del filósofo español de corte realista (fig. 4). A su vuelta, D’Ors pronunció dos conferencias en Milán y Roma con algunas de sus impresiones sobre el arte italiano que fueron publicadas posteriormente en España:

"Un poco antes de la guerra comprobé en Venecia que habían aparecido nada menos que treinta escultores geniales. Todos ellos en torno a los treinta años. De los treinta, Martini ha muerto; pero comprobé que sus relieves de la Universidad de Padua habían quedado intactos. De aquéllos vi a Marino Marini y a Messina, académicos de la Brera milanesa, y al más joven de todos, Manzù’'27.

Las esculturas expuestas, principalmente en 1948 y 1953, no respondían, sin embargo, al estilo que por esos años caracterizaba a las obras de Messina, Marini y Manzù, quienes finalizada la Segunda Guerra Mundial, como ya he señalado, experimentaron cambios considerables, sino tanto en los temas abordados, sí en la manera de resolverlos. Dejamos al margen a Martini el que, como comentaba D’Ors, fallecía en Milán en 1947.

Todos ellos eran escultores que contaban con el reconocimiento nacional tras su triunfo en las Bienales de Venecia y se ganaban progresivamente el internacional exponiendo en museos de todo el mundo. A esto se sumaba el apoyo que desde muy temprano ejercieron los críticos más importantes de su país.

En la España de posguerra, la influencia ejercida por la escultura italiana provino de dos fuentes principales. Por una parte, de las obras vistas en las dos exposiciones analizadas, por otra, con una mayor repercusión, del contacto directo con las obras italianas que tuvieron la posibilidad de analizar los escultores becados para asistir a la Academia de España en Roma durante las décadas siguientes a la posguerra ${ }^{28}$.

24 D’Ors, E., "Novísimo Glosario: Los escultores. Las juventudes”, Arriba, 30-V-1948.

25 Villacañas, C., "Entrevista con Eugenio D’Ors", Arriba, 28-XII-1948.

${ }^{26}$ Me refiero al catálogo de la exposición Francesco Messina, Garzanti Editor, Milán, 1949.

27 García Serrano, R., "Sacramento, 1. Don Eugenio se ha traído de Italia un ángel napolitano", Arriba, 8-VII-1949.

28 Sobre la influencia estilística de los escultores italianos del Novecento en la escultura española llevada a cabo entre las décadas de 1940 y 1960, véase: ARA FERnÁNDEZ, A., "La escultura española de posguerra miraba a Italia", Trasdós, n. ${ }^{\circ}$ 10, 2008, pp. 53-70. 


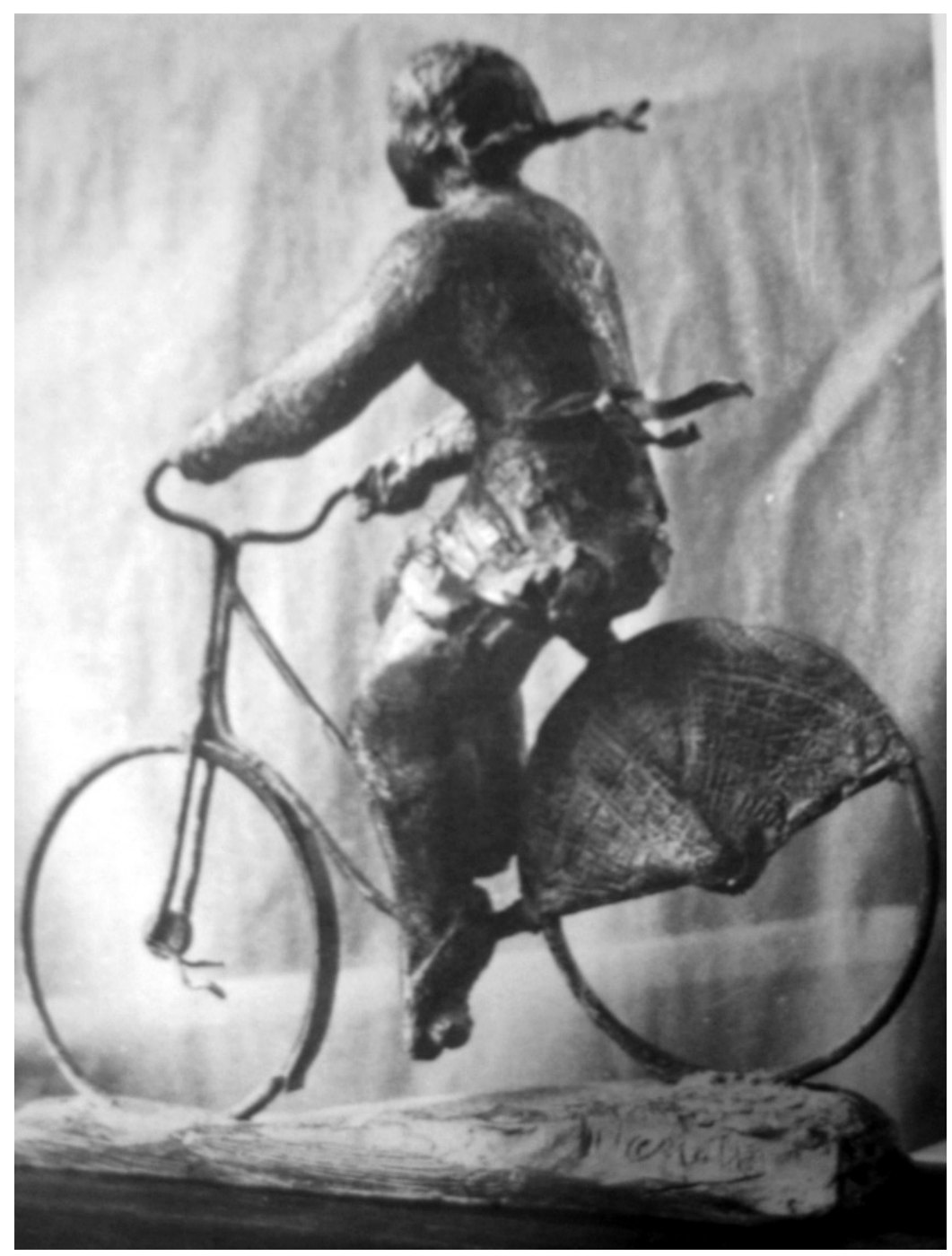

Fig. 5. Cristino Mallo, Ciclista (1946).

Otro aspecto a tener en cuenta es la circulación de información proveniente del extranjero que según Francisco Calvo Serraller existió durante los años de la inmediata posguerra en ciudades como Madrid o Barcelona ${ }^{29}$.

29 Calvo Serraller, F., “Aislamiento internacional o vacío social?, Op. cit., p. 70. 


\section{Siguiendo la estela de los escultores italianos: Cristino Mallo}

El escultor sobre el que la influencia italiana se presentaba más evidente a los ojos de la crítica fue Cristino Mallo cuyo arte discurrió por temas y conceptos que habían sido desarrollados anteriormente por el arte italiano.

Sus influencias italianas, reconocidas públicamente por el $\operatorname{artista}^{30}$, se hicieron más evidentes a partir de 1945, en una época en la que sus figuras abandonaron el estatismo y sus composiciones alcanzaron más dinamismo, como es visible en Ciclista o La comba en las que la plasmación de la alegría infantil era la única protagonista (fig. 5).

Este carácter lúdico que le caracterizó a lo largo de toda su producción, relacionado en muchos casos a temáticas deportivas, recordaba algunas obras de Giacomo Manzù en las que, si bien es cierto que los gestos de alegría en las piezas del artista italiano son más contenidos, los niños y sus juegos son el tema central de muchas de sus obras. Una característica que no pasó desapercibida a los ojos de D'Ors quien llegó a señalar: "Manzú debe de tener la edad de nuestro Cristino Mallo. En la gracia se le parece"31.

Unido a esta temática, el carácter narrativo de sus esculturas está presente, no sólo en las de bulto redondo, como en su famosa serie de figuras del Madrid de la posguerra (Serafín el buscapisos, El sereno, El afilador, La castañera, etc.), sino en algunos de sus relieves que, como Albañiles (1947) o El taller de costura (1948), le permiten crear escenas que invitan a múltiples interpretaciones narrativas. Este interés por hacer llegar al espectador una historia es una de las características esenciales de todos y cada uno de los escultores italianos analizados; práctica llevada a sus últimas consecuencias por Arturo Martini en obras como La veglia, La moglie del marinaio o Il sogno (fig. 6), todas ellas de 1931, en las que el escultor reconstruye un escenario físico-arquitectónico con esculturas.

La frescura y belleza de las obras de Mallo le valieron el reconocimiento de Eugenio D'Ors, quien situaba sus piezas a la altura de las de Marcelo Mascherini o Marino Marini, y le posibilitaron presentar su obra en los elitistas Salones de los Once organizados por la Academia Breve de Crítica de Arte en dos ocasiones ${ }^{32}$.

Con motivo de la primera de estas exposiciones, D’Ors se apropió de las palabras del crítico de arte francés Yves Revelli señalando: "Me gusta Cristino Mallo porque en su maillolismo no sigue precisamente a Maillol sino a Renoir" ${ }^{33}$.

En otra ocasión, sin abandonar sus pretensiones comparativas, señalaba:

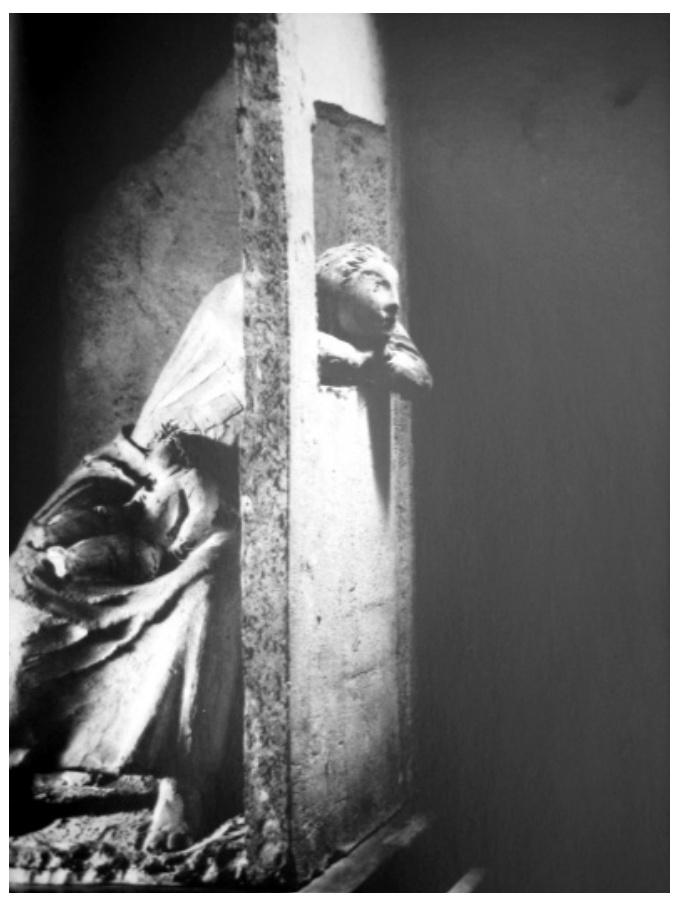

Fig. 6. Arturo Martini, La moglie del marinaio (1931).

\footnotetext{
30 Castro Arines, J., "Cristino Mallo, el escultor que vendió tres obras en la Bienal de Venecia", Informaciones, 7-VII-1953.

31 D’Ors, E., "Novísimo glosario: Los versátiles y los obstinados", Arriba, 28-V-1948.

${ }^{32}$ Me refiero al quinto Salón de los Once (1947) y al undécimo Salón (1954).

33 D’Ors, E., "Nuevo Glosario de los Once. Cristino Mallo", Arriba, 16-XII-1947.
} 


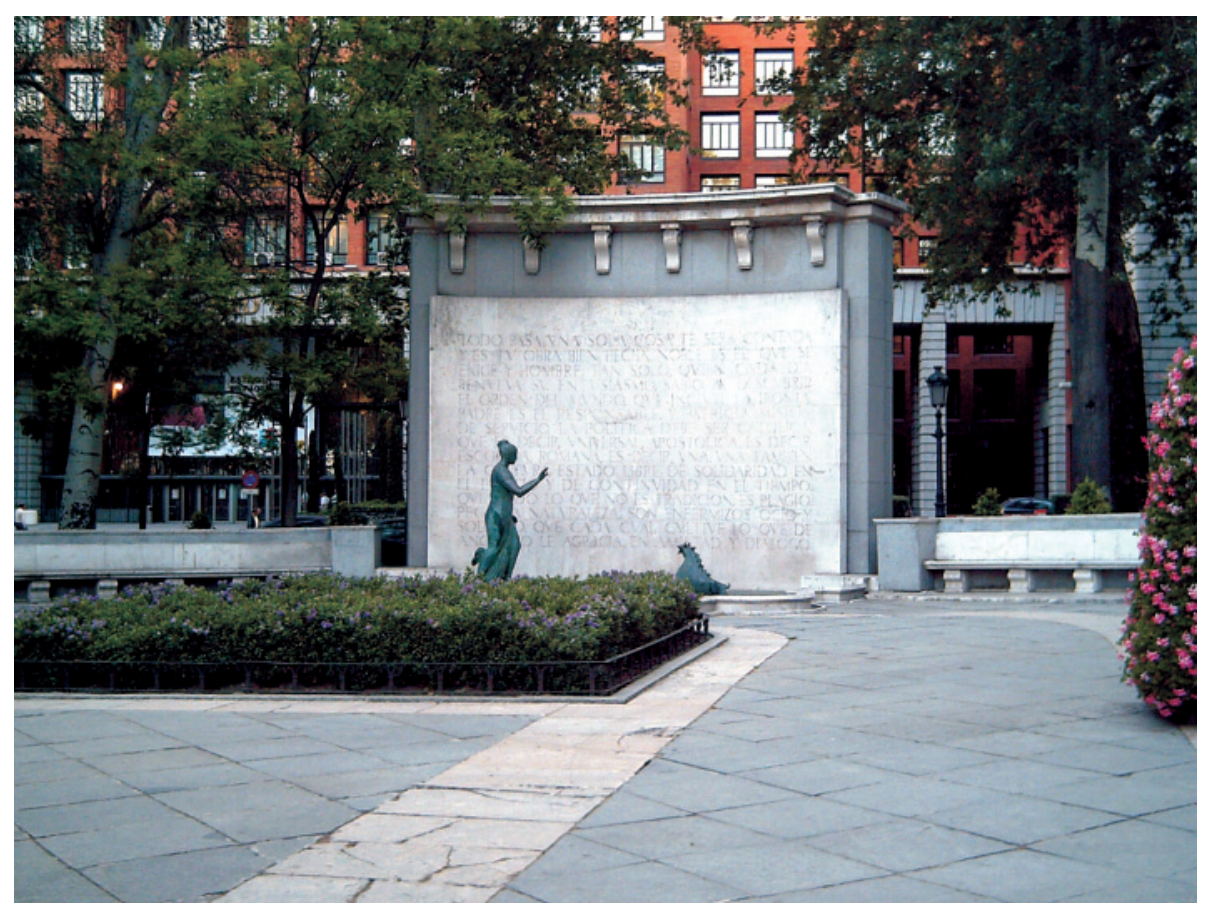

Fig. 7. Monumento a Eugenio D’Ors (1963).

"El autor de estas líneas pudo ver en 1942 y en Venecia, cómo florecían juntos hasta once escultores de genio, ninguno de los cuales alcanzaba la cuarentena. A ver si cualquier día de estos ocurre en España milagro parecido. Por de pronto ya tenemos a Cristino Mallo que les iguala a los italianos en gracia, ya que no en grandeza" 34 .

La comparación de la obra de Mallo con la de los escultores italianos fue tan repetida cada vez que se exponían algunas de sus obras que el crítico Eduardo Llosent, en un intento de defender la originalidad del artista español, contraponía "la emoción terrenal" de Mallo a la hora de representar "cualquier escena de la vida vulgar", frente a la temática mitológica de las obras de Arturo Martini; su afán por plasmar "los caracteres expresivos de la inmediata realidad" frete a la alusión de "formas etruscas y griegas" de Marino Marini, considerando a Giacomo Manzù un "impresionista" frente a la búsqueda de Cristino Mallo "en la entraña plástica del volumen"35.

Las obras de Mallo no sólo triunfaron en la España de antes y después de la guerra, sino que alcanzaron el reconocimiento del público italiano obteniendo un gran éxito en la XXVI Bienal de Venecia (1952). No es de extrañar que su trabajo gustara en Italia al estar en la línea de los planteamientos estéticos que en ese momento triunfaban en este país.

Años más tarde, en 1963, el escultor Cristino Mallo fue el encargado de realizar una alegoría femenina en bronce para el monumento que homenajea a la figura de Eugenio D'Ors en el Paseo del Prado de Madrid.

La parte arquitectónica corrió a cargo del hijo de éste, Víctor D’Ors, a la que se incorporó una medalla con el perfil del homenajeado, obra de Federico Marés (fig. 7).

\footnotetext{
${ }^{34}$ D’Ors, E., "Novísimo glosario: la IV exposición antológica de la Academia Breve”, Arriba, 6-VI-1948.
}

35 Llosent, E., "En el Estudio de Cristino Mallo", Arriba, 21-IX-1948. 
Con este monumento, Mallo homenajeaba a uno de los críticos más influyentes de su carrera artística que tanto contribuyeron a su reconocimiento en los años de la posguerra española.

Por lo comentado hasta este momento, se debe por lo tanto discernir entre lo que verdaderamente fueron influencias directas de los escultores italianos en los españoles de los intereses estratégicos de personalidades influyentes que, como Eugenio D’Ors, pretendieron que el arte español evolucionara por los mismos caminos por los que, años antes, discurría el arte italiano.

El éxito de aquellos artistas españoles que durante los años de la posguerra optaron por un arte centrado en la figura, generalmente femenina, de formas opulentas y actitudes despreocupadas, no se hizo esperar, debido, en gran medida, al apoyo ejercido por una parte de la crítica artística más influyente.

Fecha de recepción: 3-VI-2008

Fecha de aceptación: 14-X-2008 